\title{
MINIMIZAÇÃO DA ATIVIDADE PREG-ROBBING DE MINÉRIOS AURÍFEROS CARBONOSOS COM A UTILIZAÇÃO DE ADITIVOS QUÍMICOS
}

\author{
R. C. C. SANTIAGO* A. C. Q. LADEIRA \\ Centro de Desenvolvimento da Tecnologia Nuclear (CDTN/CNEN) \\ rodrigoccs15@hotmail.com.br*
}

Submetido 09/10/2017 - Aceito 08/11/2017

DOI: $10.15628 /$ holos.2017.6380

\section{RESUMO}

O presente trabalho busca simular a atividade preg-robbing da matriz carbonosa de minérios auríferos a partir de carvões minerais de diferentes níveis de maturação (antracito, betuminoso e lignito), a fim de avaliar a aplicabilidade e a funcionalidade de oito aditivos químicos em desativar/passivar a matéria carbonosa responsável por adsorver o ouro solubilizado. Ensaios de adsorção mostraram que, diferentemente do carvão antracito, o carvão betuminoso e o lignito não foram capazes de adsorver cianocomplexos de ouro em nenhuma extensão, sendo o carvão antracito, portanto, o selecionado para ensaios de desativação/passivação. Nesses ensaios, alíquotas de carvão antracito foram condicionadas por $120 \mathrm{~min}$. em soluções contendo o aditivo em concentrações que variam de 10 a $500 \mathrm{mg} \cdot \mathrm{L}^{-1}$. Ao término
\end{abstract}

do condicionamento, adicionou-se solução cianetada contendo $100 \mathrm{mgAu}^{-1} \mathrm{~L}^{-1}$, de forma a obter uma solução final

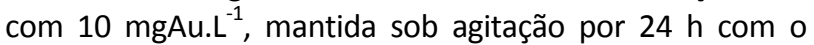
carvão. Os resultados indicaram que os condicionantes $\mathrm{C} 1$, C2, C3, S1 e Qe suprimiram o poder adsorvente do carvão em extensões que variam de $60 \%$ para baixas concentrações $\left(10 \mathrm{mg} \cdot \mathrm{L}^{-1}\right)$ a valores superiores a $80 \%$ para altas concentrações $\left(500 \mathrm{mg} . \mathrm{L}^{-1}\right)$. Avaliou-se também o efeito da variação do tempo de condicionamento $(5,30$ e 120 min.) na supressão do poder adsorvente do carvão. Para os aditivos C3 e Qe o incremento no tempo de condicionamento de 5 para $120 \mathrm{~min}$. foi acompanhado de um aumento na supressão da adsorção de $10 \%$ e $20 \%$, respectivamente.

PALAVRAS-CHAVE: Ouro, preg-robbing, condicionamento, aditivos químicos.

\section{REDUCTION OF PREG-ROBBING ACTIVITY OF CARBONACEOUS GOLD ORES WITH THE UTILIZATION OF CHEMICAL ADDITIVES}

\begin{abstract}
The present work aims to simulate the preg-robbing activity of the carbonaceous matrix of gold ores through different types of mineral coals (anthracite, bituminous and lignite), in order to evaluate the applicability and functionality of eight chemical additives in deactivating/passivate the carbonaceous matter responsible for adsorbing the solubilized gold. Adsorption tests showed that, unlike anthracite coal, bituminous coal and lignite were not able to adsorb gold in any extent, so anthracite coal was selected for deactivation/passivation assays. In these tests, aliquots of anthracite coal were conditioned for $120 \mathrm{~min}$. in solutions containing the additive in concentrations ranging from 10 to $500 \mathrm{mg} \cdot \mathrm{L}^{-1}$. At
\end{abstract}

the end of the conditioning, cyanide solution containing $100 \mathrm{mgAu}^{-\mathrm{L}^{-1}}$ was added so as to obtain a final solution of $10 \mathrm{mgAu} . \mathrm{L}^{-1}$, kept under stirring for $24 \mathrm{~h}$ with the coal. The results indicated that the $\mathrm{C} 1, \mathrm{C} 2, \mathrm{C} 3, \mathrm{~S} 1$ and Qe conditioners suppressed the adsorbent capacity of the coal in extensions ranging from $60 \%$ at low concentrations $\left(10 \mathrm{mg} \cdot \mathrm{L}^{-1}\right)$ to values higher than $80 \%$ at high concentrations ( $\left.500 \mathrm{mg} \cdot \mathrm{L}^{-1}\right)$. The effect of the conditioning time (5, 30 and $120 \mathrm{~min}$.) on suppression of the adsorbent power of the coal was also evaluated. For additives $\mathrm{C} 3$ and Qe the increase in the conditioning time from 5 to $120 \mathrm{~min}$. was accompanied by an increase in the suppression of the adsorption of $10 \%$ and $20 \%$, respectively.

KEYWORDS: Gold, preg-robbing, conditioning, chemical additives. 


\section{INTRODUÇÃO}

Por se tratar de uma entidade química em sua forma elementar metálica, caracterizada por elevadas densidade e maleabilidade e por apresentar um valor de mercado consideravelmente superior ao da grande maioria dos elementos metálicos, o beneficiamento de minérios auríferos apresenta algumas peculiaridades que o distinguem de outros métodos de tratamento (Peres, Chaves, Lins, \& Torem, 2002). Assim, perdas de ouro durante o processamento é um grande problema enfrentado pelos empreendimentos minerais que, se não propriamente identificadas, podem carrear significativas quantidades do metal para os rejeitos (Goodall, Leatham, \& Scales, 2005).

A matéria carbonosa presente em determinados minérios auríferos adsorve os cianocomplexos de ouro presentes na solução lixiviada, carreando-os para o rejeito, ocasionando perdas e comprometendo a recuperação do metal, em um fenômeno conhecido como pregrobbing. Assim como um carvão mineral, a matéria carbonosa de minérios auríferos é um componente comum de rochas metassedimentares, difundida dentro da matriz mineral e oriunda da transformação metamórfica no estado sólido do material orgânico originalmente em contato com a rocha, sendo essa transformação denominada de grafitização ou maturação e dependente da temperatura, da pressão e do tipo de material orgânico precursor (Afenya, 1991; Miller, Wan, \& Díaz, 2005). Com as semelhanças químicas e físicas existentes entre os carvões minerais e a matéria carbonosa de minérios auríferos é possível simular a atividade preg-robbing desses minérios utilizando como fonte de matéria carbonosa carvões minerais.

Muitas técnicas têm sido empregadas na tentativa de reduzir o efeito deletério da matéria carbonosa na etapa de cianetação do processamento hidrometalúrgico de minérios auríferos, incluindo a utilização de adsorventes de ouro (carvão ativado ou resinas) concomitantemente ao processo de cianetação, a flotação da matéria carbonosa do minério, a desativação/passivação da matéria ativa por oxidação (ustulação, oxidação sob pressão, oxidação química ou bioquímica) e a utilização de aditivos químicos de superfície capazes de desativar/passivar a matéria carbonosa (Afenya, 1991; Miller et al., 2005). Até o momento, os tratamentos oxidativos de ustulação e oxidação sob pressão têm se mostrado mais efetivos e viáveis, sendo prática industrial recorrente em todo o mundo há décadas. No entanto, com os constantes incrementos no rigor das legislações destinadas ao controle de emissões atmosféricas de gases tóxicos e nocivos ao meio ambiente, a aplicação dessas técnicas tem se tornado cada vez mais complexa e onerosa. Com isso, o desenvolvimento e a aplicação de técnicas hidrometalúrgicas se apresentam como alternativas atraentes para possíveis substituições dos métodos oxidativos (Marden \& House, 2009).

Nesse cenário, surgem determinados aditivos químicos de superfície com capacidade de desativar/passivar a matéria carbonosa através de fenômenos como a adsorção seletiva, o molhamento e o revestimento da superfície do componente de carbono nativo da matéria carbonosa (Afenya, 1991; Miller et al., 2005). O presente trabalho busca simular a atividade pregrobbing de minérios auríferos utilizando como fonte de matéria carbonosa carvões minerais de três diferentes níveis de maturação (antracito, betuminoso e lignito), a fim de avaliar a aplicabilidade e a funcionalidade de oito aditivos químicos em desativar/passivar a matéria 
responsável por adsorver o ouro solubilizado e identificar possíveis relações entre a estrutura da matriz carbonosa desses carvões e a de minérios auríferos carbonosos.

\section{METODOLOGIA}

\subsection{Matéria carbonosa - Carvões minerais}

Os carvões minerais utilizados para simular a matéria carbonosa de minérios auríferos foram fornecidos pelo Banco de Carvão do Instituo de Energia do Colégio de Ciências da Terra e dos Minerais da Universidade do Estado da Pensilvânia. A Tabela 1 apresenta as características desses carvões conforme data sheet disponibilizada pelo fornecedor.

Tabela 1: Características dos carvões minerais.

\begin{tabular}{c|c|c|c|c|c|c}
\hline Carvão & $\begin{array}{c}\text { Grau de } \\
\text { maturação }\end{array}$ & $\begin{array}{c}\text { Carbono } \\
\text { (\%) } \\
\text { (dmmf) }^{\mathbf{1}}\end{array}$ & $\begin{array}{c}\text { Hidrogênio } \\
\text { (\%) } \\
\text { (dmmf) }^{\mathbf{1}}\end{array}$ & $\begin{array}{c}\text { Enxofre } \\
\text { (\%) } \\
\text { (dry) }^{\mathbf{2}}\end{array}$ & $\begin{array}{c}\text { Cinzas } \\
\text { (\%) } \\
\text { (dry) }^{\mathbf{2}}\end{array}$ & $\begin{array}{c}\text { Voláteis } \\
\text { (\%) } \\
\text { (dmmf) }^{\mathbf{1}}\end{array}$ \\
\hline CM1 & Antracito & 91,5 & 4,1 & 0,50 & 11,2 & 3,9 \\
CM2 & Betuminoso & 82,3 & 6,3 & 0,44 & 6,6 & 49,7 \\
CM3 & Lignito & 74,1 & 4,5 & 0,74 & 9,6 & 61,6 \\
\hline
\end{tabular}

${ }^{1}$ dmmf (dry, mineral-matter-free): Em base seca, sem material mineral.

${ }^{2}$ dry: Em base seca.

Antes de serem utilizados nos ensaios de adsorção, todos os carvões, recebidos com granulometria inferior a $841 \mu \mathrm{m}$, foram deslamados a úmido em peneira com malha de $37 \mu \mathrm{m}$.

\subsection{Aditivos químicos}

A Tabela 2 apresenta os aditivos químicos utilizados no condicionamento dos carvões minerais, com sua respectiva identificação, o seu fabricante e a sua descrição conforme FISPQ.

Tabela 2: Aditivos químicos.

\begin{tabular}{|c|c|c|c|}
\hline Aditivo químico & $\begin{array}{c}\text { Identificaçã } \\
0\end{array}$ & Fabricante & Descrição conforme FISPQ \\
\hline E/PE MIN 011/17 & $\mathrm{C} 1$ & Clariant & $\begin{array}{l}\text { Sal sódico de um produto de condensação } \\
\text { aromático sulfatado em solução aquosa }\end{array}$ \\
\hline E/PE MIN 012/17 & $\mathrm{C} 2$ & Clariant & Composto derivado de ácido graxo \\
\hline E/PE MIN 013/17 & C3 & Clariant & Destilado de petróleo \\
\hline $\begin{array}{c}\text { Aero } 633 \\
\text { Depressant }\end{array}$ & S1 & Solvay & Mistura ( $p$-cresol, m-metilfenol) \\
\hline $\begin{array}{l}\text { Aero } 8860 \text { GL GCA } \\
\text { Depresant }\end{array}$ & S2 & Solvay & $\begin{array}{l}\text { Poliacrilamida modificada, mistura } \\
\text { (metabisulfito de sódio, etileno glicol, } \\
\text { sulfato de amônio, metacrilato de 2- } \\
\text { hidroxietilo) }\end{array}$ \\
\hline $\begin{array}{c}\text { Cyquest } 3223 \\
\text { Antiprecipitant }\end{array}$ & S3 & Solvay & Poliacrilato de sódio em água \\
\hline $\begin{array}{c}\text { Cyquest } 40 \mathrm{E} \\
\text { Antiprecipitant }\end{array}$ & S4 & Solvay & $\begin{array}{c}\text { Ácido policarboxílico modificado em água, } \\
\text { mistura (ácido maléico) }\end{array}$ \\
\hline Querosene & Qe & Petrovila & Mistura de hidrocarbonetos parafínicos, \\
\hline
\end{tabular}




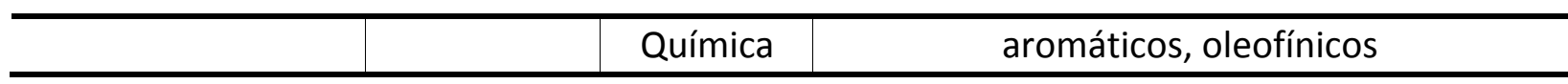

\subsection{Caracterização dos carvões minerais}

A fim de complementar a caracterização dos carvões minerais disponibilizadas pelo fornecedor, as fases cristalinas dos carvões foram identificados por difratometria de raios- $X$ (DRX), através de um difratômetro RIGAKU D/MAX ULTIMA PLUS (40kV e $30 \mathrm{~mA}$ ) com anodo de cobre como fonte de raios-X $\left(\mathrm{Cu} \mathrm{K}_{\alpha 1}=1.5405 \AA\right.$ e $\mathrm{Cu} \mathrm{K} \mathrm{K}_{\alpha 2}=1.5443 \AA$ ), goniômetro em configuração $\theta-\theta$ e monocromador de grafite. Os difratogramas foram obtidos com $2 \theta$ variando de 4 a $80^{\circ}$ em velocidade de $4^{\circ} / \mathrm{min}$ e passo de $0,02^{\circ}$.

\subsection{Adsorção de cianocomplexos de ouro em carvão mineral}

Nos ensaios de adsorção de ouro, triplicatas de alíquotas de carvões minerais de massa variando de 0 a $1,0 \mathrm{~g}$ foram mantidas em contato com $50 \mathrm{~mL}$ de solução contendo $10 \mathrm{mgAu} . \mathrm{L}^{-1}$ $\left(50,8 \mu \mathrm{molAu} . \mathrm{L}^{-1}\right)$ e $100 \mathrm{mgNaCN} . \mathrm{L}^{-1}\left(2,0 \mathrm{mmolNaCN} . \mathrm{L}^{-1}\right)$ em pH entre 10,5 e 11,5 , sob agitação constante de $150 \mathrm{~min}^{-1}$ a $25^{\circ} \mathrm{C}$ durante 24 horas. Ao fim do tempo de contato a polpa foi filtrada e a solução residual encaminhada para análise química para a determinação da concentração final de Au. A diferença entre a concentração de ouro em solução antes e após o ensaio de adsorção foi registrada e o percentual adsorvido calculado.

O carvão que apresentou a melhor capacidade de carregamento foi utilizado em ensaios de adsorção (desativação/passivação) após ser condicionado com os aditivos químicos. Nesses ensaios, alíquotas de $0,8 \mathrm{~g}$ de carvão foram condicionadas em $\mathrm{pH}$ entre 10,5-11,5, por 120 minutos, em $45 \mathrm{~mL}$ de solução contendo o aditivo em cinco diferentes concentrações (10, $100,200,300$ e $\left.500 \mathrm{mg} \cdot \mathrm{L}^{-1}\right)$. Ao término do condicionamento, adicionou-se $5 \mathrm{~mL}$ de solução cianetada contendo $100 \mathrm{mgAu}^{-L^{-1}}\left(507,7 \mu \mathrm{molAu} . \mathrm{L}^{-1}\right)$ e $3500 \mathrm{mgNaCN} . \mathrm{L}^{-1}\left(0,06 \mathrm{molNaCN} . \mathrm{L}^{-1}\right)$, de forma a obter uma solução final com 10 mgAu. $\mathrm{L}^{-1}\left(50,8 \mu \mathrm{molAu} . \mathrm{L}^{-1}\right)$ e $350 \mathrm{mgNaCN} . \mathrm{L}^{-1}$ $\left(7,1 \mathrm{mmolNaCN} . \mathrm{L}^{-1}\right)$ mantida sob agitação por $24 \mathrm{~h}$ com a massa de carvão.

Os aditivos químicos que apresentaram resultados satisfatórios, no que tange a inibição da adsorção de cianocomplexos de ouro pelo carvão, foram utilizados em concentrações de $500 \mathrm{mg} \cdot \mathrm{L}^{-1}$ em ensaios de desativação/passivação, realizados nas condições acima mencionadas, a fim de avaliar o efeito da variação do tempo de condicionamento na supressão do poder adsorvente do material adsorvente. Foram avaliados tempos de condicionamento de 5, 30 e 120 minutos.

As determinações das concentrações de $A u$ em soluções foram realizadas por espectrometria de absorção atômica em um espectrômetro VARIAN AA240FS.

\section{RESULTADOS E DISCUSSÕES}

\subsection{Caracterização dos carvões minerais}

À medida que o grau de maturação da matéria carbonosa aumenta (antracito> betuminoso > sub-betuminoso > lignito) há uma correspondente diminuição no seu teor de umidade e de materiais voláteis (isto é, metano e dióxido de carbono), bem como um aumento na porcentagem de carbono, uma diminuição gradual na porcentagem de oxigênio e, em última 
análise, ao se aproximar do grau antracito, uma diminuição acentuada no teor de hidrogênio (Miller, 2005; Miller et al., 2005). Essa tendência pode ser observada na Tabela 1 do Tópico 2.1, que apresenta as principais características dos carvões utilizados ao longo desse estudo. 0 carvão mineral antracito é o que apresenta o maior teor de carbono (91,5\%), o menor teor de hidrogênio $(4,1 \%)$ e o menor teor de materiais voláteis $(3,9 \%)$ em sua porção orgânica, seguido pelo carvão betuminoso com $82,3 \%$ de carbono, $6,3 \%$ de hidrogênio e $49,7 \%$ de voláteis, e pelo carvão lignito com $74,1 \%$ de carbono, $4,5 \%$ de hidrogênio e $61,6 \%$ de voláteis. Observa-se também que o carvão antracito é o que possui o maior teor de cinzas $(11,2 \%)$ e, por consequência, a maior porção inorgânica, seguido pelo carvão lignito $(9,6 \%)$ e pelo betuminoso $(6,6 \%)$.

A Figura 1 apresenta os perfis de difração de raios- $X$ dos três carvões minerais, realizados sem que os mesmos fossem desmineralizados. Nota-se que todas as amostras exibiram altas intensidades de background, o que indica que os carvões são compostos por uma porção considerável de material (carbono) amorfo. Além disso, percebe-se em todos os difratogramas a presença de um pico (002) em aproximadamente $26^{\circ}(d=3,35 \AA$ ) , um indicativo de que os carvões também contêm algumas estruturas grafíticas ordenadas (carbono cristalino). Essas observações sugerem que os cristalitos presentes na matéria orgânica apresentam estruturas intermediárias entre a estrutura do grafite e a de um material amorfo, estrutura intermediária esta denominada de turbostrática. A maior acentuação do pico (002) nas proximidades de $26^{\circ}$ do difratograma do carvão antracito (CM1) é um possível indicativo de que este é o carvão mineral que possui a estrutura grafítica mais desenvolvida, ou seja, o carvão que possui a rede cristalina mais ordenada, seguido pelo carvão betuminoso (CM2) e pelo carvão lignito (CM1). Essas observações são suportadas por Lu, Sahajwalla, Kong e Harris (2001) e Sonibare, Haeger e Foley (2010).

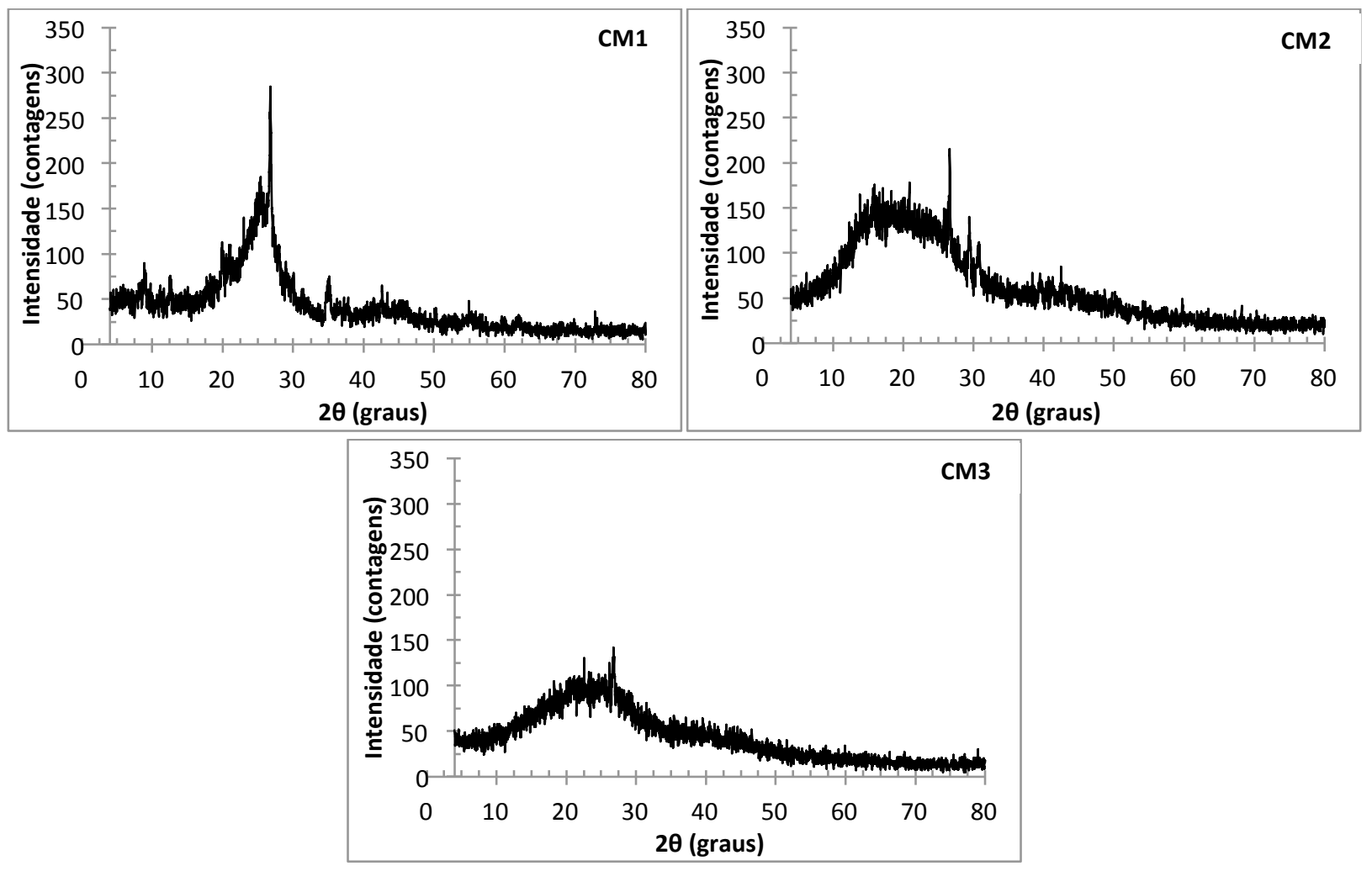

Figura 1: Difratogramas de raios-X dos carvões minerais (CM1, CM2 e CM3). 


\subsection{Ensaios de adsorção}

Os ensaios de adsorção mostraram que o carvão mineral antracito foi capaz de adsorver cianocomplexos de ouro, enquanto o carvão mineral betuminoso e o carvão mineral lignito não. Essa tendência também foi observada por Sarpong, Tien e Asare (2010), em um trabalho realizado com amostras de diferentes carvões minerais (antracito, betuminoso, sub-betuminoso e lignito) para avaliar a capacidade de fungos Phanerochaete chrysosporium em suprimir a adsorção de cianocomplexos de ouro pela matéria carbonosa.

A diferença na capacidade adsortiva dos carvões minerais de diferentes níveis de maturação vai de encontro ao proposto por Ibrado e Fuerstenau (1992), que em um estudo em que analisaram a relevância da natureza, mais especificamente da estrutura do material carbonoso no processo de adsorção de ouro, relataram que a adsorção cianocomplexos do metal ocorre preferencialmente nas estruturas grafíticas presentes na rede cristalina desses materiais. Assim, a presença de estruturas grafíticas mais desenvolvidas e a maior ordenação de sua rede cristalina podem ser apontadas como fatores preponderantes para que o carvão mineral antracito apresente capacidade de adsorver cianocomplexos de ouro na faixa de $\mathrm{pH}$ estudada $(10,5-11,5)$.

Contudo, o carvão mineral antracito (CM1) foi o selecionado para os ensaios de desativação/passivação a partir do condicionamento prévio com os aditivos químicos. A Figura 2 apresenta o percentual de ouro adsorvido e a capacidade de carregamento desse carvão em função de sua massa. Observa-se que alíquotas com massas entre 0,7 e 1,0 g foram capazes de adsorver aproximadamente $90 \%$ do ouro presente em solução, enquanto a capacidade de carregamento máxima, 920 gAu.tcarvão $^{-1}$, foi reportada em 0,3 g de carvão.

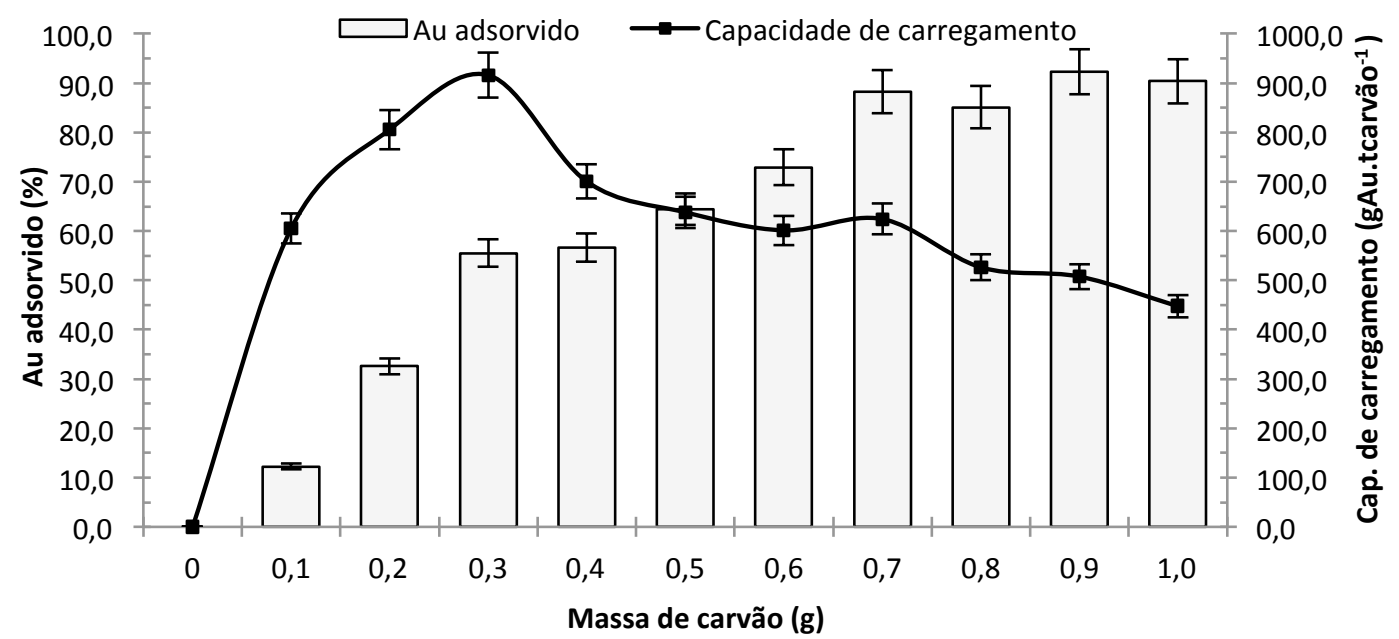

Figura 2: \% de ouro adsorvido e a capacidade de carregamento do carvão mineral antracito (CM1).

A Figura 3 apresenta o percentual de ouro adsorvido pelo carvão antracito nos ensaios de adsorção após o condicionamento prévio com os oito aditivos químicos, em cinco concentrações diferentes, por 120 minutos. Para fins comparativos, a figura apresenta também o percentual de ouro adsorvido por 0,8 g do carvão (aproximadamente 90\%) sem que fossem utilizados aditivos químicos em seu condicionamento.

Os resultados indicam que em baixas concentrações, $10 \mathrm{mg} \cdot \mathrm{L}^{-1}$, apenas os aditivos C2 e C3 foram capazes de suprimir o poder adsorvente do carvão antracito em uma extensão 
considerável, aproximadamente $60 \%$. Em concentrações de 100, 200, 300 e 500 mg. $\mathrm{L}^{-1}$, os aditivos C2, C3 e Qe apresentaram comportamentos semelhantes, com valores de supressão entre 70 e $80 \%$.

Em concentrações de 200 e $300 \mathrm{mg} \cdot \mathrm{L}^{-1}$, o aditivo S1 suprimiu o poder adsorvente do carvão em até $60 \%$. Já em concentrações de $500 \mathrm{mg} \cdot \mathrm{L}^{-1}$ esse mesmo aditivo apresentou valor de supressão próximo a 70\%. O aditivo C1 proporcionou supressões com valores de 55 e $70 \%$ quando utilizado em concentrações de 300 e $500 \mathrm{mg} . \mathrm{L}^{-1}$, respectivamente. Já os demais aditivos (S2, S3 e S4) não se mostraram eficazes para suprimir o poder de adsorção do carvão antracito.

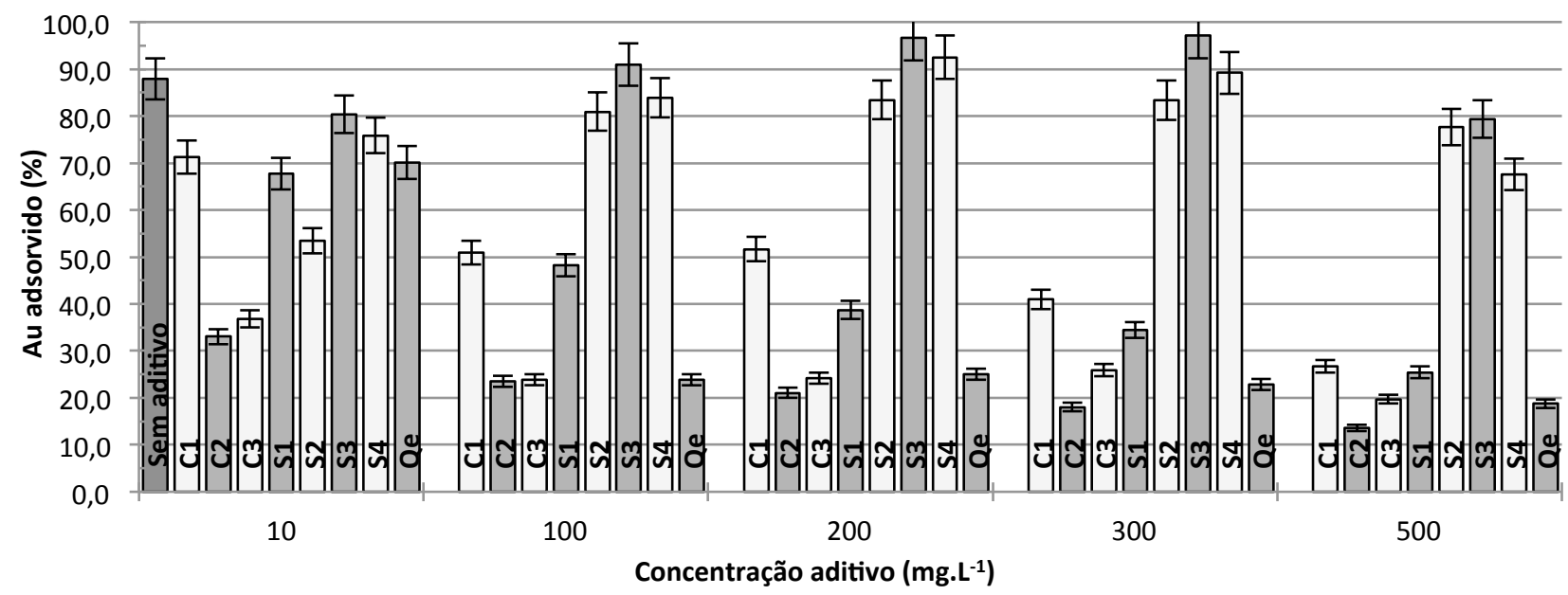

Figura 3: \% de ouro adsorvido pelo carvão antracito em função da concentração do aditivo

A fim de avaliar o efeito da variação do tempo de condicionamento na supressão do poder adsorvente do carvão mineral antracito, foram realizados ensaios com os cinco aditivos que obtiveram os melhores desempenhos, em concentrações de $500 \mathrm{mg}$. $\mathrm{L}^{-1}$, em três diferentes tempos de condicionamento, 5, 30 e 120 minutos. A Figura 4 apresenta o percentual de ouro adsorvido pelo material adsorvente com e sem a ação dos condicionantes.

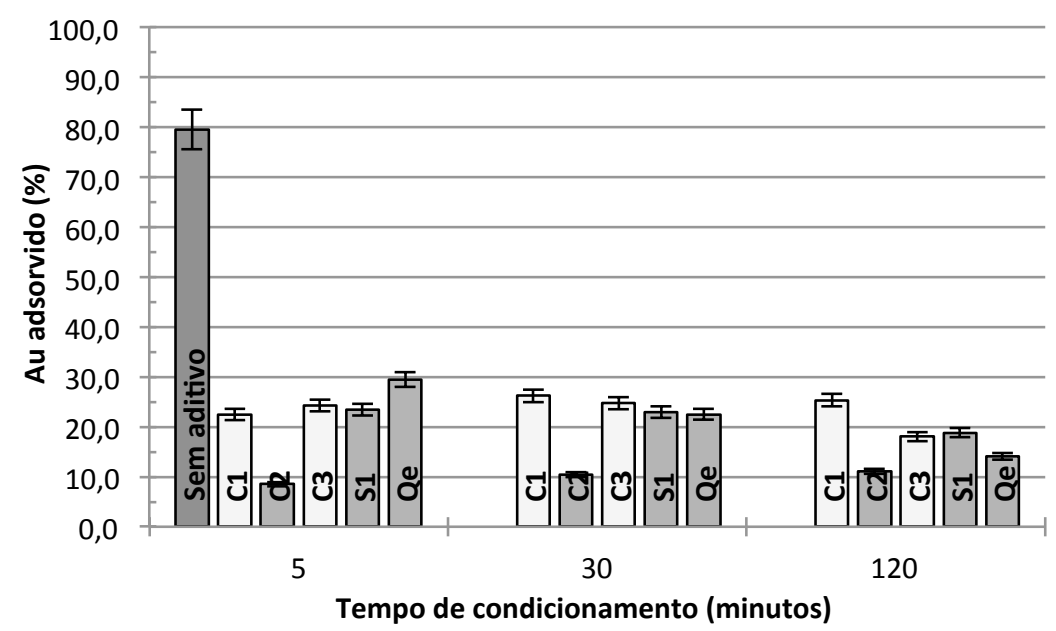

Figura 4: \% de ouro adsorvido pelo carvão antracito em função do tempo de condicionamento.

Nota-se que para os aditivos C1, C2 e S1 o incremento no tempo de condicionamento do carvão não apresentou efeito significativo na supressão da adsorção de ouro. Independentemente do tempo utilizado, a adsorção foi suprimida em valores próximos a $70 \%$ com a utilização do aditivo C1, valores superiores a $80 \%$ para o C2 e valores próximos a $75 \%$ para 
o S1. Já para os aditivos C3 e Qe, o incremento no tempo de condicionamento do carvão ocasionou um ligeiro aumento na supressão da adsorção de cianocomplexos de ouro pelo material adsorvente. Com um tempo de condicionamento de 5 minutos, a utilização do aditivo C3 foi capaz de suprimir a adsorção de ouro em aproximadamente $65 \%$, enquanto que com um tempo 120 minutos, supressão superior a 75\% foi alcançada. Esse aumento é mais pronunciado com a utilização do aditivo Qe, sendo este responsável por uma supressão de aproximadamente $60 \%$ quando utilizado um tempo de condicionamento de 5 minutos e $80 \%$ em um tempo de 120 minutos.

Os resultados até aqui encontrados apresentam valores de supressão no poder de adsorção do material adsorvente próximos aos reportados por publicações referentes a esse tema (Abotsi \& Asare, 1987; Adams \& Burger, 1998; Dimov \& Hart, 2016). Os resultados mais promissores possibilitaram reduções na capacidade de carregamento de ouro em valores entre 75 e $90 \%$.

\section{CONCLUSÃO}

A difratometria de raios $X$ dos carvões minerais indicou que os cristalitos presentes na matéria orgânica desses materiais apresentam estruturas intermediárias (turbostráticas) entre a estrutura do grafite e a de um material amorfo. $O$ fato de possuir uma estrutura grafítica mais desenvolvida e uma rede cristalina mais ordenada faz com que o carvão antracito apresente capacidade de adsorver cianocomplexos de ouro, enquanto o carvão betuminoso e o lignito não. Contudo, acredita-se que a estrutura da matéria carbonosa de minérios auríferos com atividade preg-robbing se assemelha a estrutura de carvões minerais com grau de maturação próximo ao antracito.

Os resultados dos ensaios de desativação/passivação indicaram que os condicionantes C1, C2, C3, S1 e Qe apresentaram capacidade em suprimir o poder adsorvente do carvão em extensões que variam de $60 \%$ para baixas concentrações $\left(10 \mathrm{mg} \cdot \mathrm{L}^{-1}\right)$ a valores superiores a $80 \%$ para altas concentrações (500 mg. $\mathrm{L}^{-1}$ ). Para os aditivos C3 e Qe o incremento de 5 para 120 minutos no tempo de condicionamento do carvão antracito foi acompanhado de um aumento na supressão da adsorção de $10 \%$ e $20 \%$, respectivamente. Os resultados demonstraram uma superioridade no desempenho dos aditivos C2 e C3 em face ao desempenho dos demais.

Há de se destacar que todo o estudo foi realizado em um carvão antracito, utilizado como modelo para simular a complexa matriz carbonosa de minérios auríferos com atividade pregrobbing, podendo ser necessárias algumas adequações para os ensaios futuros em um minério aurífero carbonoso, que ratificarão os resultados até aqui encontrados.

\section{AGRADECIMENTOS}

Os autores agradecem ao suporte financeiro do INCT-Acqua, da FAPEMIG, do CNPQ e da CAPES. 


\section{REFERÊNCIAS BIBLIOGRÁFICAS}

Abotsi, G. M. K., \& Asare, K. O. (1987). Surface Chemistry of Carbonaceous Gold Ores II: Effects of Organic Additives on Gold Adsorption from Cyanide Solution. International Journal of Mineral Processing. 21, 225-239.

Adams, M. D., \& Burger, A. M. (1998). Characterization and Blinding of Carbonaceous PregRobbers in Gold Ores. Minerals Engineering. 11(10), 919-927.

Afenya, P. M. (1991). Treatment of Carbonaceous Refractory Gold Ores. Minerals Engineering. 4(7-11), 1043-1055.

Dimov, S. S., \& Hart, B. (2016). Study on Surfactants for Passivation of Naturally Occuring Carbonaceous Matter in Gold Bearing Ores. XXVIII International Mineral Processing Congress Proceedings. Canadá: Québec City.

Goodall, W. R., Leatham, J. D., \& Scales, P. J. (2005). A New Method for Determination of PregRobbing in Gol Ores. Minerals Engineering.18, 1135-1141.

Ibrado, A. S., \& Fuerstenau, D. W. (1992) Effect of the Structure of Carbon Adsorbents on the Adsorption of Gold Cyanide. Hydrometallurgy. 30, 243-256.

Lu, L., Sahajwalla, V., Kong, C., \& Harris, D. (2001). Quantitative X-Ray Diffraction Analysis and its Application to Various Coals. Carbon. 39, 1821-1833.

Marsden, J. O., \& House, C. L. (2009). The Chemistry of Gold Extraction (2a ed.). USA: Society for Mining, Metallurgy and Exploration.

Miller, B. G. Coal Energy Systems. USA: Elsevier Academic Press.

Miller, J. D., Wan, R. -Y., \& DÍAZ, X. (2005). Preg-Robbing Gold Ores. In Adams, M. D. (Ed.). Advances in Gold Ore Processing. Australia: B. A. Wills.

Peres, A. E. C., Chaves, A. P., Lins, F. A. F., \& Torem, M. L. (2002). Beneficiamento de Minérios de Ouro. In Trindade, R. de B. E., \& Filho, O. L. (Ed.). Extração de Ouro - Princípios, Tecnologia e Meio Ambiente. Rio de Janeiro.

Sarpong, G. O., Tien, M., \& Asare, K. O. (2010) Mycohydrometallurgy: Coal Model for Potential Reduction of Preg-Robbing Capacity of Carbonaceous Gold Ores Using The Fungus, Phanerochaete Chrysosporium. Hydrometallurgy. 102, 66-72.

Sonibare, O. O., Haeger, T., \& Foley, S. F. (2010). Structural Characterization of Nigerian Coals by X-ray diffraction, Raman and FTIR Spectroscopy. Energy. 35, 5347-5353. 